\title{
Glomus Jugulare Tumor: Selective Catecholamine Screening - A Golden Miss?
}

\author{
${ }^{1}$ Amit Rastogi, ${ }^{2}$ Vansh Priya, ${ }^{3}$ Paurush Ambesh, ${ }^{4}$ Vertika Sachan
}

\begin{abstract}
Glomus jugulare tumor is a type of paraganglioma which has an association with catecholamine secretion but only in $<5 \%$ of cases. Any such occult or undetected catecholamine-secreting tumor poses anesthetic challenges in the perioperative period. A routine catecholamine assay and rigorous hemodynamic monitoring in such cases minimize perioperative anesthetic complications.
\end{abstract}

Keywords: Catecholamine, Paragangliomas, Tumor

How to cite this article: Rastogi A, Priya V, Ambesh P, Sachan V. Glomus Jugulare Tumor: Selective Catecholamine Screening - A Golden Miss? World J Endoc Surg 2017;9(2):65-67.

\section{Source of support: Nil}

\section{Conflict of interest: None}

\section{INTRODUCTION}

Catecholamine-secreting paragangliomas (CSPs) are relatively rare. The common term "glomus tumor" is often used interchangeably with "paraganglioma". These tumors are locally invasive and arise from the glomus body at the dome of the jugular bulb and commonly occur in the 5th to 6th decade of life. Glomus jugulare tumors, which are capable of secreting catecholamines, are seen in 3 to $5 \%$ of cases. ${ }^{1}$

Failure to diagnose such a catecholamine-secreting glomus tumor preoperatively can result in serious perioperative hemodynamic alterations. Such patients require special anesthetic considerations during their excision or any other surgical procedure.

\section{CASE REPORT}

We report a case of a 53-year-old female with right glomus jugulare tumor posted in intervention neuroradiology

\footnotetext{
${ }^{1}$ Assistant Professor, ${ }^{2,4}$ Senior Resident, ${ }^{3}$ Junior Resident

1,2,4 Department of Anaesthesiology, Sanjay Gandhi Postgraduate Institute of Medical Sciences, Lucknow, Uttar Pradesh, India

${ }^{3}$ Department of General Medicine, Moti Lal Nehru Medical College, Allahabad, Uttar Pradesh, India

Corresponding Author: Amit Rastogi, Assistant Professor Department of Anaesthesiology, Sanjay Gandhi Postgraduate Institute of Medical Sciences, Lucknow, Uttar Pradesh, India Phone: +915222495530, e-mail: toshigsvm@gmail.com
}

unit for embolization through right transfemoral route. After obtaining written informed consent from the patient, we wish to report this case.

The patient was apparently asymptomatic 2 years back when she developed right-sided hearing loss, vertigo, and pain in right hemicranium. The patient had no other associated comorbid disease and there were no features suggestive of raised intracranial pressure. Magnetic resonance imaging showed intensely enhancing soft tissue mass lesion in the right jugular bulb which was extending into the mastoid bone (Fig. 1).

Intraoperative monitoring included a 5-lead electrocardiogram, noninvasive blood pressure, pulse oximetry, esophageal temperature, and bispectral index. Induction of anesthesia was achieved using IV propofol $(140 \mathrm{mg})$ and fentanyl $(150 \mu \mathrm{g})$. Endotracheal intubation was facilitated with IV vecuronium hydrochloride $(8 \mathrm{mg})$. The bladder was catheterized to monitor urine output. Anesthesia was maintained with an IV infusion of propofol $(100-150 \mu \mathrm{g} / \mathrm{kg} / \mathrm{min})$ and intermittent boluses of fentanyl and vecuronium.

Thirty minutes after the commencement of procedure, there was a sudden rise in blood pressure (up to $220 / 120 \mathrm{~mm} \mathrm{Hg}$ ) with tachycardia (140-160/min) and continued even after increasing the depth of anesthesia. We prompted the radiologist for interruption of procedure, which resulted in control of hemodynamics in next 5 minutes. Extreme perturbations of blood pressure and heart rate were again noticed on resumption of the procedure. Suspecting this particular tumor to be a catecholamine-secreting variant, left radial artery

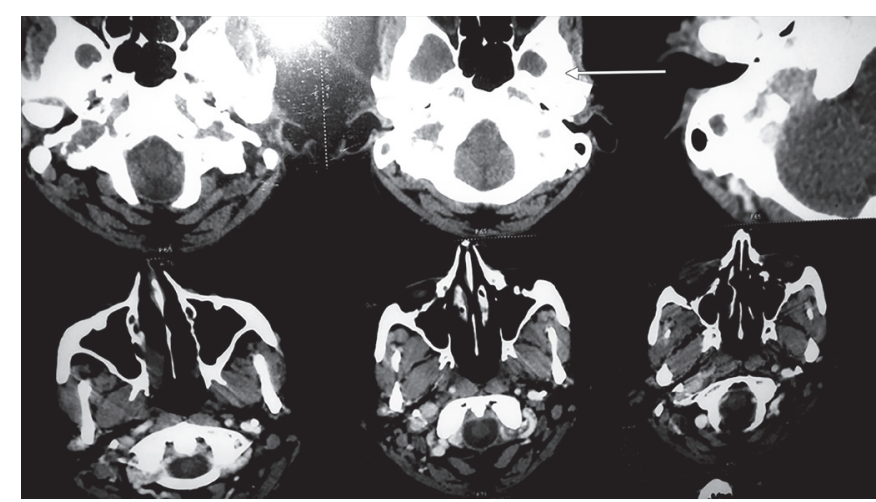

Fig. 1: Arrow showing intensely enhancing soft tissue mass lesion in the right jugular bulb which was extending into the mastoid bone 
cannulation was done and invasive blood pressure monitoring was started. Left femoral central venous cannulation was also done and sodium nitroprusside (SNP) infusion (3-4 $\mu \mathrm{g} / \mathrm{kg} / \mathrm{min}$ ) was started. Intermittent IV boluses of esmolol $(0.3-0.5 \mathrm{mg} / \mathrm{kg})$ were given to control heart rate during the entire procedure. On completion of the procedure, SNP infusion was gradually tapered and then stopped. The residual effect of muscle relaxant was neutralized with a mixture of neostigmine and glycopyrrolate, and trachea was extubated.

\section{DISCUSSION}

Approximately 3 to $4 \%$ of head and neck paragangliomas secrete catecholamines. ${ }^{2}$ The majority of CSPs produce norepinephrine, with only a few secreting epinephrine or dopamine.

Clinical presentation of glomus jugulare tumor depends on their vascularity and invasion into the adjacent structures. Sometimes presenting symptoms to the clinician may be due to the cranial nerves involvement. ${ }^{3} \mathrm{In}$ $<5 \%$ of cases, glomus jugulare tumors are catecholamine secreting. ${ }^{4}$ Multicentricity has traditionally been reported in $10 \%$ of patients with sporadic paragangliomas. ${ }^{4}$

Catecholamine assays are fundamental to the diagnosis of CSP. Recent recommendations for biochemical testing of secreting tumors include high-performance liquid phase chromatography measurements of plasmafree metanephrine and normetanephrine) or 24-hour urine fractionated metanephrines. ${ }^{4}$ Unlike catecholamines, which may be secreted episodically, metanephrines are continuously produced by tumor cells. Detailed history and examination particularly of cardiovascular system are of paramount importance. Left ventricular hypertrophy is seen in virtually all patients with CSP. Furthermore, prolonged exposure to increased concentrations of circulating catecholamines may result in dilated cardiomyopathy linked with ventricular failure. The evaluation includes chest skiagram, assays for creatine kinase, electrocardiography, and echocardiogram.

Preoperatively, the vagus nerve is most commonly affected. ${ }^{5}$ Glossopharyngeal and hypoglossal nerves are also at risk. Impaired sensory and motor function, especially of the vagus nerve, can increase the risk of postoperative aspiration, which may occur in nearly $25 \%$ of patients. ${ }^{6}$ The risk of airway obstruction following cranial nerve injury is less than the risk of aspiration but is nonetheless real. Fortunately, in our case, there was no cranial nerve involvement.

In our patient, catecholamine assay was not done as there were no clinical features suggestive of catecholamine excess and cardiac workup was normal. Hypertensive episodes and tachycardia were noticed only during the procedure. Invasive hemodynamic monitoring in the form of arterial blood pressure helped us in adequate control of blood pressure while using vasodilator infusions. Preoperative embolization of glomus tumors reduces both intraoperative blood loss and operative time. There have been reports documenting hypertensive crisis or wide fluctuations in blood pressure, ${ }^{7}$ theoretically from tumor necrosis and subsequent release of catecholamines into systemic circulation. Teranishi et $\mathrm{al}^{8}$ recommended screening of catecholamine secretion for all patients with a glomus tumor.

The question of when and what to test is an important one. Should serum and urine catecholamine levels be checked in all patients with glomus tumors or only those with symptoms? Clinically, the most common finding is hypertension ( $90 \%$ of CSPs), either paroxysmal or sustained. Patients who only experience hypertensive paroxysms (sometimes asymptomatic) are easily overlooked ${ }^{4}$ by normal blood pressure values. Levit et $\mathrm{al}^{9}$ suggest that all patients with craniocervical paragangliomas should have serum and urine levels checked. Jackson et $\mathrm{al}^{5}$ recommend formal laboratory testing only with a suggestive clinical history. The problem with this later strategy is that undiagnosed pheochromocytomas lead to high perioperative morbidity and mortality.

While there are fewer reports of undiagnosed catecholamine-secreting glomus tumors, there is every reason to believe perioperative morbidity would be high without proper preoperative evaluation and preparation. Kremer et $\mathrm{a}^{10}$ routinely tested serum catecholamines in patients with glomus tumors regardless of the history and physical examination and have found catecholamine levels as high as eight times normal without clinical symptoms. This suggests the need to preoperatively check serum catecholamine levels in all patients with suspected glomus tumors.

A high index of suspicion, with testing for cranial nerve involvement, measurement of serum catecholamine levels, appropriate perioperative pharmacological control, and invasive hemodynamic monitoring can reduce perioperative complications in such secretory paragangliomas.

\section{REFERENCES}

1. Jensen NF. Glomus tumors of the head and neck: anesthetic considerations. Anesth Analg 1994 Jan;78(1):112-119.

2. Jackson CG, Cueva RA, Thedinger BA, Glasscock ME 3rd. Conservation surgery for glomus jugulare tumors: the value of early diagnosis. Laryngoscope 1990 Oct;100(10 Pt 1): 1031-1036.

3. Yadav M, Gopinath R, Kumar BR, Padhy S, Ram AA, Chintha SK. Anaesthetic management in a patient with 
glomus jugulare tumour for ankle surgery. Int J Anesthetic Anesthesiol 2014 Sep;1:1-2.

4. Colen TY, Mihm FG, Mason TP, Roberson JB. Catecholaminesecreting paragangliomas: recent progress in diagnosis and perioperative management. Skull Base 2009 Nov;19(6): 377-385.

5. Jackson CG, Harris PF, Glasscock ME 3rd, Fritsch M, Dimitrov E, Johnson GD, Poe DS. Diagnosis and management of paragangliomas of the skull base. Am J Surg 1990 Apr;159(4): 389-393.

6. Jackson CG, Cueva RA, Thedinger BA, Glasscock ME 3rd. Cranial nerve preservation in lesions of the jugular fossa. Otolaryngol Head Neck Surg 1991 Nov;105(5): 687-693.
7. Motegi H, Terasaka S, Yamaguchi S, Kobayashi H, Asaoka K, Iwasaki Y. A case of catecholamine-secreting glomus jugulare tumor: treatment strategy and perioperative management [in Japanese]. No Shinkei Geka 2008 Nov;36(11):1029-1034

8. Teranishi $Y$, Kohno M, Sora S, Sato H, Haruyama N. Perioperative management of catecholamine-secreting glomus jugulare tumors. J Neurol Surg Rep 2014 Aug;75(1):e170-e174.

9. Levit SA, Sheps SG, Espinosa RE, Remine WH, Harrison EG. Catecholamine-secreting paraganglioma of glomus-jugulare region resembling pheochromocytoma. N Eng J Med 1969 Oct;281:805-811.

10. Kremer R, Michel RP, Posner B, Wang NS, Lafond GP, Crawhall JC. Catecholamine secreting paraganglioma of glomus jugulare region. Am J Med Sci 1989 Jan;297(1):46-48. 